\title{
An innovative and qualitative research methodology course in graduate master nursing program of Southern Taiwan
}

\author{
Ya-Lie Ku*1, Pei-Yu Lee ${ }^{2}$ \\ ${ }^{1}$ College of Nursing, Department of Nursing, Fooyin University, Kaohsiung City, Taiwan, ROC \\ ${ }^{2}$ Department of Early Childhood Care and Education, Cheng Shiu University, Taiwan, ROC
}

Received: August 30, 2021

DOI: $10.5430 / j n e p . v 12 n 3 p 41$
Accepted: October 10, 2021

Online Published: November 2, 2021

\begin{abstract}
Background: A quantitative worldview has long dominated nursing research, causing it to lack the humanized inspiration of a qualitative worldview. This study sought to develop and evaluate an innovative and qualitative research methodology course in one graduate master nursing program of Southern Taiwan.

Methods: Qualitative research design was to develop the innovative and qualitative research methodology course with training the Listening, Empathy, and Presence (LEP) skills and the qualitative worldview of master nursing students. This study was approved by the improved teaching project grant from a University (FYU1008-109-04) during March 1 to October 31, 2020.

Results: The results identified that first, the innovative and qualitative research methodology course incorporated the course objectives, teaching content, and innovative strategies in two elective credits with content validity as.86. Additionally, the nine master nursing students reported that the quantitative worldview was closely associated with numbers, statistics, and measurement, whereas the qualitative worldview had a greater tendency to entail aspects of humanism with conversations, communication, and caring among nine master nursing students.

Conclusions: The innovative and qualitative research methodology course could train master nursing students to master qualitative research skills and help nursing educators achieve balance with mutual coexistence and understanding between qualitative and quantitative approaches.
\end{abstract}

Key Words: Methodology, Nursing education, Qualitative research

\section{INTRODUCTION}

Nursing research began with a quantitative worldview and incorporated additional advancements in positivism; consequently, qualitative research was routinely marginalized. Reis et al. ${ }^{[1]}$ found that among $274 \mathrm{PhD}$ dissertations at Brazil State University between 1990 and 2015, 52.6\% used a qualitative design, whereas only $2 \%$ of 51 master's theses used a qualitative design. Similarly, Sun et al. ${ }^{[2]}$ interviewed
16 Taiwanese nursing master's students from graduate programs at seven different universities using a semi-structured approach, soliciting reasons for using a qualitative design, misunderstandings and perceptions of the difficulty of undertaking qualitative studies, and time and energy involved. Additionally, Holtslander et al. ${ }^{[3]}$ reported that qualitative studies are viewed as complicated because no formulas are given to follow and researchers must use their own judg-

\footnotetext{
*Correspondence: Ya-Lie Ku; Email: ns126@fy.edu.tw; Address: College of Nursing, Department of Nursing, Fooyin University, Kaohsiung City 83102, Taiwan, ROC. 
ment to select appropriate methods, giving rise to difficulties in teaching qualitative research courses. Because literature indicating less percentage of master nursing students choosing qualitative studies as their theses, the rationale included feeling difficulties to approach with no formula to follow. Therefore, the qualitative research methodology course itself is necessary for training master nursing students to master qualitative research skills. The purpose of this study was to introduce one innovative and qualitative research methodology course that was implemented in a graduate master nursing program of southern Taiwan.

\section{METHOD}

Qualitative research design was to develop and evaluate the innovative and qualitative research course with training the Listening, Empathy, and Presence (LEP) skills and the qualitative worldview of master nursing students. The innovative and qualitative research course was constructed by the authors based on the literature evidences in Taiwan. Three nursing education experts were invited to evaluate the course by design (40 scores), qualities of teachers (30 scores), teaching resources (20 scores), and other standards (10 scores). Additionally, graduate nursing students were demonstrated their qualitative and quantitative worldviews by drawing the pictures after completing this innovative qualitative methodology research course.

The innovative teaching strategies were immersed into the qualitative nursing research methodology course including lecture, parable stories telling, simulation by action and per- formance, probing, reflection, and group discussion with illustrating the photos and videos. Through the innovative teaching process, master nursing students could really experience in the qualitative and textual environment with verbal and nonverbal behaviors. This study was approved by the improved teaching project grant from a University (FYU1008109-04) during March 1 to October 31, 2020.

\section{RESULTS}

\subsection{Goals, content, and teaching strategies of the quali- tative research methodology course}

The innovative and qualitative research course was a twocredit course that met for 2 hours per week over 18 weeks with content validity as .86 evaluating by three nursing education experts. Goals for the course were for students to (1) understand and explore qualitative research concepts and methods; (2) attain the characteristics of a qualitative researcher; (3) apply a qualitative interview and analysis process to a simulation case; (4) explore and analyze the qualitative themes of the simulation interview case; (5) review the qualitative research literature to distinguish history, ground theory, ethnography, phenomenology, narrative study, action research, and feminist studies; and (6) complete one qualitative research proposal, including preparation of a research topic, background, purpose, literature review, design, sampling, data collection and analysis, ethical considerations, and references. The content and teaching strategies of the qualitative research methodology course are shown in Table 1.

Table 1. Content and teaching strategies of the qualitative research methodology course

\begin{tabular}{|l|l|l|}
\hline Week & Course Content & Teaching Strategies \\
\hline 1 & Course Description/Exploring the Qualitative Research & Lecture \& Parable \\
2 & Training the Skills of Qualitative Researcher: Listening, Empathy, Presence (LEP) & Case Analysis \& Video Teaching \\
\hline 3 & Qualitative Individually Interview Skills & Practical Operation \\
4 & Qualitative Group Interview Skills & Practical Operation \\
5 & Qualitative Content Analysis/Rigor Process of Qualitative Research & Experience Learning \\
\hline 6 & History Research Methodology & \\
7 & Ground Theory Research Methodology & \\
8 & Ethnography Research Methodology & Lecture \& Reflection \\
9 & Phenomenology Research Methodology & \\
10 & Narrative Study Methodology & \\
11 & Participating Action Research Methodology & Lecture \& Guiding \\
12 & Feminist Theory Research Methodology & Lecture \& Guiding \\
\hline 13 & Qualitative Research Proposal: Background, Purpose & Lecture \& Guiding \\
14 & Qualitative Research Proposal: Literature Review & Oral Presentations \&Comments \\
\hline
\end{tabular}


As shown in Table 1, the authors introduced the main teaching content and methods as follows. The first week focused on exploration of qualitative research as the instructor led students to adopt micro and macro perspectives to reflect on their daily lives and nursing work by distinguishing when quantitative or qualitative worldviews were involved. ${ }^{[4]}$ The three essential research paradigms of ontology, epistemology, and methodology were later introduced, as well as positivism, post-positivism, critical theory, constructivism, and qualitative systematic review research methods. ${ }^{[5-7]}$

The second week introduced training in the characteristics of a qualitative researcher, including the skills of LEP. The instructor initially proposed sensitivity as the prerequisite for cultivating tacit knowledge, meaning that when a qualitative interviewer has a similar experience, he or she can naturally connect with an interviewee by applying LEP skills. Additionally, the instructor reminded students that listening might precede empathy during the process of presence, which entails noting not only what an interviewee talks about, but also what he or she avoids talking about. ${ }^{[8]}$ In this manner, the interviewer may discern deeply held inner thoughts of the interviewee through a cycle of empathy based on mutual understanding. ${ }^{[9,10]}$

The third week introduced skills for individual interviews, training students in skills such as preparing interview materials and constructing interview guidelines, as well as principles and ethical concerns. ${ }^{[11-13]}$ Afterward, a simulation was held where students gained actual experience in the individual way of qualitative interview process: they were divided into several groups, each having a leader who acted as an interviewer while the instructor played the role of interviewee on a specified topic. Other students acted as observers responsible for recording verbal and nonverbal behaviors, which were recorded in the interview transcripts. They would listen to interview recordings and conduct content analyses by inductively categorizing meaningful units with the generation and naming of different themes. ${ }^{[10,14]}$

The fourth week trained students in distinguishing focus and reference groups as well as in conducting Delphi group discussion interviews. ${ }^{[15-17]}$ With respect to the focus group interview, the instructor acted as a moderator in a simulation with six-eight students selected for a focus group; the rest students of the class acted as observers to record verbal and nonverbal behaviors. The moderator conducted interviews, employing various stages and levels of the process, on one specified topic. The focus group members shared and discussed ideas until there is no further new topic to be explored. The moderator did not participate in the discussion because the role was limited to leading, probing, and encouraging discussion among participants.

Reference group interviews tend to be applied in discussions of political and economic issues, and stakeholders are invited to participate. For instance, here, the instructor again served as a moderator, but this time, students were divided into six groups representing nursing organizations in the northern, middle, southern, eastern, island, and minority regions. The moderator proposed one political or economic issue for representatives of each organization to discuss, enabling them to share their opinions and suggestions. The moderator only clarified discussion topics but refrained from making suggestions during communication and discussion among representatives. Additionally, the moderator offered conclusions before closing the interview. With respect to Delphi group discussion interviews, Lin, Lu, and Chung ${ }^{[16]}$ explained the process of building nursing evaluation criteria by taking domestic and foreign literature into account to develop the initial questionnaire; conducting an expert meeting; using snowball sampling for distributing a questionnaire survey; and finally, 29 item-quality nursing indicators were developed by construct, process, and outcomes.

The fifth week introduced qualitative content analysis; ${ }^{[10]}$ "Spiritual distress experienced by cancer patients" was taken as an example, ${ }^{[18]}$ and quasi-statistical analysis ${ }^{[10]}$ was used to develop a code book, according to research topics and purposes, to conduct inductive data analysis; "Establishing the validity of a spiritual distress scale for cancer patients hospitalized in southern Taiwan" ${ }^{[19]}$ as used for an example. Immersion and crystallization analyse ${ }^{[10]}$ are often used in instances of individual and deeply qualitative research such as autobiographies, memoirs, or similar. These require long-term recall of experiences among research subjects; for example, in the exploration of the life experiences of an aged woman in a military housing community that conducted for this study was probed through reminiscence over photos. ${ }^{[20]}$ Protocol analysis and editing analysis ${ }^{[10]}$ were fit into ground theory, ethnography, phenomenology, and narrative studies using the examples of "Exploring live experiences of elderly tinnitus patients"[21] and "Exploring the spiritual growth experiences of nurses caring for terminally ill patients". ${ }^{[22]}$ Additionally, the rigorous process of qualitative research was introduced trustworthiness, entailing credibility, transferability, dependability, and confirmability as well as quality evaluation of qualitative research, ${ }^{[10]}$ entailing sensitivity to context, commitment and rigor, transparency and coherence, impact and importance to clinical practice. ${ }^{[23]}$

The sixth week presented historical research methodology, as well as the process of systematic data collection and analysis concerning past events. It was emphasized that firsthand 
data are preferred to identify relationships between causes and effects as well as consistent development to explain past phenomena and understand current conditions; this process yields evidence-based data to predict the future. Initially, the instructor introduced Florence Nightingale, the American History Association and Midwest Nursing History Research Center, and finally the nursing history of China and Taiwan. ${ }^{[24]}$ Examples for historical research included "Playing an active role in maternal-infant care: using oral history to explore a midwife's career in postwar Taiwan", ${ }^{[25]}$ "Research into oral history related to the management of the first registered nursing home in Taiwan", ${ }^{26]}$ "Using oral historical study to explore the changes of psychiatric medical care model in the Yuli hospital," and "Exploring the development of structural and professional issues concerning the Psychiatric Mental Health Nurses Association". [27,28]

The seventh week featured ground theory methodology, which is similar to a tree, where themes are explored as branches; probing deeper into the earth is also possible. Initially, the instructor introduced origins, appropriate areas, two stages of purposive and theoretical samplings, interviews, and data analysis skills. ${ }^{[29]}$ Subsequently, the instructor used "Introducing grounded theory: Taking the study of quality of family care of frail elders in Taiwan as an example to explain the methodology of ground theory and how to further develop the measurement scale based on the ground theory data". ${ }^{[30,31]}$ Following the above instruction, groups of students practiced data analysis approaches, including open, axial, selective coding, and writing theoretical memos.

The eighth week addressed using an ethnographic methodology to explore and interpret the cultural meaning of a group of people, taking account of their daily life norms, rituals, habits, and rules; this was done to introduce the relationship between ethnography and culture as well as the categories of ethnography. ${ }^{[32]}$ Finally, the instructor used an anthropological-cultural research methodology to introduce the micro and macro levels as well as the subjective and objective research definitions and methodology, ${ }^{[33]}$ this discussion cited "Chinese cultural beliefs about breast cancer and breast self-examination" ${ }^{[34]}$ as an example for further explanation. Following this instruction, groups of students practiced cultural interviews, including the use of grand tour questions, specific questions, and attribute questions with macro and micro as well as etic and emic data analysis.

The ninth week concerned phenomena methodology with an initial introduction to different schools, life worlds, conscious tendencies, and essences, as well as the concept of existence without judgment proposed by Husserl and Heidegger; ${ }^{[35,36]}$ the key course material was "A retrospective study of mother's perspective of the lived experience of family anticipatory loss of a child from a terminal brain tumor". ${ }^{[37]}$ Subsequently, the instructor further introduced the seven steps of data analysis by Edward and Welch, ${ }^{[38]}$ and the two steps of data analysis by Hasanvand et al. ${ }^{[39]}$ that groups of students practiced data analysis by following the above instruction. The tenth week consisted of a narrative study, using the narrative research of Lieblich, Mashiach, and Zilber ${ }^{[40]}$ as a model for introducing the differences between stories and narrative; "Self-transformation through suffering from the illness: a narrative research of a woman undergoing Gynecological diseases and treatment process" ${ }^{\text {"[1] }}$ served as the example. Finally, the instructor introduced the four dimensions of narrative analysis, which include integrate-content, integrate-pattern, category-content, and category-pattern; ${ }^{[40]}$ groups of students then practiced data analysis by following the above instruction.

The eleventh week, featured participating action research methodology, which consisted of introductions to origins and historical changes, characters and categories, values and principles, and practice strategies with eight principles as the essences of the participating action research methodology. ${ }^{[42]}$ In this unit, key topics were community related, community leading, abilities cultivating, various methods, information sharing, producing social action, process oriented, and ethical considerations. ${ }^{[42]}$ Key materials for this lesson were "Action teaching methods to teach the course of spiritual nursing for elders to nursing students" $[43]$ and "Exploring the case study of life-review and reminiscence activities for elderly women". ${ }^{[4]}$ Finally, the instructor led groups of students in experiencing the process of participating action research.

The twelfth week featured feminist research methodology and was similar to the participating action research methodology lesson as it emphasized interventions and changes. However, feminist research entails empowerment of participants to maintain the ability to change. The instructor initially introduced the characteristics of feminist research methodology, including consciousness raising, empowerment, and emancipation; ${ }^{[45]}$ the corresponding seven principles treat women not only as research subjects, but also assist them in changing their circumstances or confronting their health problems. From the feminist perspective, the research process is influenced by these values, the relationship between researcher and the women is reciprocal, the researcher takes a personal role as an agent of change, women can gain emancipation, social revolution activities are conducted, and the goals of changing women's circumstances and health problems are achieved. ${ }^{[46]}$ "Constructing women's community of mental health in Tainan: An action research" ${ }^{\text {"47] }}$ was the 
primary course material. Furthermore, Professor Nai-Ying Ko's assistance in arranging free HIV screening for pregnant women as part of welfare policy was upheld as a paradigm of feminist research.

\subsection{Quantitative and qualitative worldviews of master nursing students}

In this innovative and qualitative research methodology course, nine master nursing students participated in the improved teaching plan that applied practice, experience, and simulation strategies. These strategies allowed the students to learn the quantitative worldview as closely associated with numbers, statistics, and measurement, whereas the qualitative worldview had a greater tendency to entail aspects of humanism with talking, communication, and caring.

\section{DISCUSSION AND CONCLUSION}

The innovative and qualitative research methodology course was developed based on the Taiwanese literature evidences with .86 content validity evaluated by three nursing education experts. However, the literature based on this innovative and qualitative research methodology course in this study were majorly coming from Taiwan and lack of literature from foreign references. This is the limitation of this study that this innovative and qualitative research methodology course might not be able to be generalized into the master nursing programs of other countries. Nevertheless, this study could indicate there are enough Taiwanese evidences-based quali- tative research literature for nursing researchers to apply into their qualitative research course.

In conclusion, the innovative and qualitative research methodology course incorporated the course objectives, teaching content, and innovative strategies could provide as the reference for nursing educators who are also interested in teaching the qualitative nursing research course. The authors expected the content and teaching methods of the qualitative research methodology course to stimulate enthusiasm of qualitative research in nursing academics once again. The various nursing schools will value the qualitative course if they are willing to invest more time and attention to cultivate the qualitative talents of nursing researchers. The innovative and qualitative research methodology course could then train master nursing students to master qualitative research skills and help nursing educators achieve balance with mutual coexistence and understanding between qualitative and quantitative approaches. In the long run, the nursing research paradigm will be in the balance state between qualitative and quantitative fields, achieving the goal of nursing as the gentle of art and science.

\section{ACKNOWLEDgements}

This study was funded by the improving teaching plan (FYU1008-109-04) supported from the Minister of Education, Taiwan.

\section{CONFlicts OF INTEREST Disclosure}

The authors declare that there is no conflict of interest.

\section{REFERENCES}

[1] Reis JCC, Correia MDL, de Souza Lacerda Botelho MT, et al. Knowledge production in a post-graduation program in Nursing. Journal of Nursing. 2018; 12(11): 3052-3059. https://doi.org/10.5205/ 1981-8963-v12i11a236089p3052-3059-2018

[2] Sun FK, Long A, Chiang CY, et al. Rationale underpinning postgraduate student nurses' choice of research methods used for their masters' theses. Nursing Education in Practice. 2018; 33: 127-132. PMid:30293054 https://doi.org/10.1016/j.nepr.2018.10 .002

[3] Holtslander LF, Racine L, Furniss S, et al. Developing and piloting an online graduate nursing course focused on experiential learning of qualitative research methods. Journal of Nursing Education. 2012; 51: 345-348. PMid:22533499 https ://doi .org/10 .3928/0148 4834-20120427-03

[4] Ku YL. Nursing research approach in the daily nursing practice. Journal of Nursing Research and Practice. 2019; 3(1): 15. https: //www . pulsus. com/scholarly-articles

[5] Lu PP, Ting SS, Chen ML, et al. The positioning of nursing research in the academic studies: The origin and development of qualitative and quantitative studies. The Journal of Nursing. 2005; 52(6): 76-81.

[6] Mu PF. Qualitative systematic review research method. Original Far Nursing. 2014; 8(3): 5-11.

Published by Sciedu Press
[7] Yang CI, Lee LH, Tzeng WC. The relationship between qualitative research positivism. The Journal of Nursing. 2008; 55(5): 64-68.

[8] Nee W. The Characteristics of God Worker. Taiwan Gospel Book. 2002.

[9] Hsieh MH, Wang, HH. The concept and implications on presence of inter subjective nurse-patient relationship. TZU CHI Nursing Journal. 2011; 10(4): 28-63

[10] Lee S. Nursing Research and Application (4th). Taipei: Farseeing Publication. 2011.

[11] Cheng LF. Qualitative research series workshop-(2). Bulletin of Women and Gender Studies. 2000; 56: 8-10.

[12] Jian CY. The exploring ethic issues of conducting qualitative interviewing research. Guidance Quarterly. 2005; 41(1): 47-57. https : //doi.org/10.29742/GQ.200503.0006

[13] Yang CL. Qualitative research series workshop-(1). Bulletin of Women and Gender Studies. 2000; 56: 2-7. https://doi.org/ 10.6256/FWGS. 2000.56.2

[14] Griesheim UH, Lundman B. Qualitative content analysis in nursing research: concepts, procedures and measures to achieve trustworthiness. Nursing Education Today. 2004; 24: 105-112. PMid:14769454 https://doi.org/10.1016/j.nedt.2003.10.001 
[15] Chang MY, Hsu LL. Qualitative research: An introduction to focus group methodology and its application. The Journal of Nursing. 2006; 53(2): 67-72.

[16] Lin CF, Lu MS, Chung CC. The development of nursing quality indicators. Chang Gung Nursing. 2007; 18(4): 465-474. http: //dx.doi.org/10.6386/CGN.200712_18(4).0001

[17] Lin JD, Yen CF, Chen MH. Qualitative research method: Models and steps of interviewing. Journal of Disability Research. 2005; 3(2): 122-136. https://doi .org/10.30072/JDR . 200506. 0005

[18] Ku YL. Spiritual distress experienced by cancer patients - Develop a spiritual care for cancer patients. Taiwan Journal of Hospice Palliative Care. 2005; 10(3): 221-233.

[19] Ku YL, Kuo SM, Yao CY. Establishing the validity of a spiritual distress scale for cancer patients hospitalized in southern Taiwan. International Journal of Palliative Nursing. 2010; 16(3): 134 138. PMid:20357706 https ://doi.org/10.12968/ijpn. 2010 .16.3.47325

[20] $\mathrm{Ku} \mathrm{YL,} \mathrm{Ku} \mathrm{CK,} \mathrm{Ku} \mathrm{JL.} \mathrm{Exploration} \mathrm{of} \mathrm{life} \mathrm{experiences} \mathrm{of} \mathrm{an} \mathrm{aged}$ woman in a military housing community through reminiscing on photos. The Journal of Nursing. 2009; 56(1): 52-62.

[21] Chen YL, Chen SM, Ku YL. Exploring live experiences of elderly tinnitus patients. Chang Gung Nursing. 2014; 25(3): 256-271.

[22] Liu YH, YangWP, Ku YL. Exploring the spiritual growth experiences of nurses caring for terminally ill patients. Journal of Nursing \& Patient Care. 2017; 2(1): 1-6.

[23] Yardley L. Dilemmas in qualitative health research. Psychology and Health. 2000; 15: 215-228. https://doi.org/10.1080/088704 40008400302

[24] Chou CC, Lin HP. The nursing history research journey: Experience sharing. The Journal of Nursing. 2011; 58(5): 29-33. PMid:28080876 https://doi.org/10.7748/ns.24.29.33.s46

[25] Liang HF, Wu KM. Playing an active role in maternal-infant care: Using oral history to explore a midwife's career in postwar Taiwan. Journal of Nursing and Healthcare Research. 2013; 9(3): 237-247.

[26] Tsay SF, Wu JH. Research into oral history related to the management of the first registered nursing home in Taiwan. The Journal of Nursing. 2006; 53(3): 34-43.

[27] Chang SE, Rong JR, Chang TJ. Using oral historical study to explore the changes of psychiatric medical care model in the Yuli hospital. The Journal of Psychiatric Mental Health Nursing. 2015; 10(2): 5-18

[28] Shiau SJ, Huang JY, Chou CF, et al. Exploring the development of structural and professional issues concerning the psychiatric mental health nurse association. The Journal of Psychiatric Mental Health Nursing. 2007; 2(1): 1-12.

[29] Wang SY, Windsor C, Yates P. Introduction to ground theory. The Journal of Nursing. 2012; 59(1): 90-94.

[30] Shyu YI. Introducing grounded theory: Taking the study of "quality of family care frail elders in Taiwan" as an example. Nursing Research. 1996; 4(3): 263-272. https://doi.org/10.7081/NR.1 99609.0263
[31] Chang TC, Lotus Shyu YI, Chen MC, et al. Predictors of competence in family caregivers of dementia patients. The Journal of Nursing. 2012; 59(6): 25-35. https://doi .org/10.6224/JN.59.6.25

[32] Chuang YH, Abbey J. Ethnography and nursing research. The Journal of Nursing. 2005; 52(6): 49-56. PMid:15660143 https: //doi.org/10.1188/05. ONF.49-56

[33] Fetterman DM. Ethnography (2nd edition). Sage Publications. 1998.

[34] $\mathrm{Ku}$ YL. Chinese cultural beliefs about breast cancer and breast selfexamination. Taiwan Journal of Hospice Palliative Care. 2004; 9(4): 313-335.

[35] Chen SC. Phenomenological methodology and the application in nursing research. New Taipei Journal of Nursing. 2000; 2(2): $117-$ 123. https://doi .org/10.6540/NT JN . 2000.2.011

[36] Huang YP, Kellett UM, John WS, et al. Analysis phenomenology and application to nursing research. The Journal of Nursing. 2006; 53(2): 49-58. https://doi.org/10.6224/JN.53.2.49

[37] Lou HL, Mu PF, Wong TT, et al. A retrospective study of mother's perspective of the lived experience of family anticipatory loss of a child from a terminal brain tumor. Cancer Nursing. 2015; 38(4): 298 304. PMid:25010249 https://doi.org/10.1097/NCC. 000000 0000000178

[38] Edward KL, Welch T. The extension of Colaizzi's method of phenomenology inquiry. Contemporary Nurse. 2011; 39(2): 163-171. PMid:22551429 https : //doi.org/10.5172/conu.2011.163

[39] Hasanvand S, Ashktorab T, Seyedfatemi N, et al. The analysis of phenomenological experiences based on Giorgi method. Advances in Nursing \& Midwifery. 2016; 25(89): 69-80.

[40] Lieblich A, Mashiach RT, Zilber T. Reading, Analysis, and Interpretation of Narrative Research (Y. G. Wu translate). Chiayi: Water Stone Publishers. 2008.

[41] Cheng PF, Chou CC. Self-transformation through suffering from the illness: a narrative research of a woman undergoing Gynecological diseases and treatment process. Journal of Life Education. 2013; 5(1): 91-124.

[42] Yeh L. Participatory action research and its utilization. New Taipei Journal of Nursing. 2010; 12(2): 59-68.

[43] Ko JK, Lee PY, Ku YL. Action teaching methods to teach the course of spiritual nursing for elders to nursing students. VGH Nursing. 2014; 31(1): 12-19.

[44] Lee PY, Ko JK, Ku YL. Exploring the case study of life-review and reminiscence activities for the elderly women. Taiwan Journal of Hospice Palliative Care. 2016; 21(3): 273-288.

[45] Lu ZYJ, Lin HK, Chang PF. Application of feminist participatory research in nursing research. The Journal of Nursing. 2003; 50(2): 57-60.

[46] Ku YL. Women Health and Nursing (pp.101-135). Yu et al. (Eds), Women Health. Taipei, Taiwan: Farseeing Publication. 2014.

[47] Shu BC, Hsieh HC. Constructing women's community of mental health in Tainan: An action research. The Journal of Nursing. 1999; 46(1): 31-36. 